\title{
Effect of a target-controlled infusion of remifentanil in combination with desflurane during the "maintenance" phase of general anesthesia
}

\author{
Myoung-Keun Shin ${ }^{1}$, Haeng Seon Shim ${ }^{1}$, Geun Young Yang ${ }^{1}$, and Woo Sung Sung ${ }^{2}$
}

Department of Anesthesiology and Pain Medicine, ' Samsung Changwon Hospital, Sungkyunkwan University School of Medicine, Changwon, ${ }^{2}$ Jinyeong Samsung Hospital, Gimhae, Korea

Background: The goal of this study was to determine the optimal target-controlled concentration of remifentanil combined with desflurane, by using a more widely and decreasing end-tidal concentration of desflurane.

Methods: Ninety ASA I patients, who underwent general anesthesia for elective orthopedic or extremity surgeries, were registered and randomly allocated to receive either a target-controlled concentration of $1 \mathrm{ng} / \mathrm{ml}$ (group R1), 2 $\mathrm{ng} / \mathrm{ml}$ (group R2) remifentanil, or desflurane only without remifentanil infusion (group D). Mean arterial pressure (MAP) and heart rate (HR) were recorded at 5-min intervals from after a 10-15 min period of surgical incision to before a 10-min period prior to the end of an operation. End-tidal concentration of desflurane was increased or decreased in proportion to the changes in MAP and HR. If the value of bispectral index (BIS) was from 60-62 for more than 2 min or systolic blood pressure would fall below $90 \mathrm{mmHg}$, the patient was excluded from the study to prevent a risk of "explicit awareness" and shock.

Results: The end-tidal desflurane concentration was lower in the group receiving $1 \mathrm{ng} / \mathrm{ml}(5.2 \pm 0.5 \mathrm{vol} \%$; P < $0.001)$ and $2 \mathrm{ng} / \mathrm{ml}$ remifenanil $(4.4 \pm 0.5$ vol\%; $\mathrm{P}<0.001)$ compared to patients in group $\mathrm{D}(7.9 \pm 0.5 \mathrm{vol} \%)$.

Conclusions: We recommend the use of $2 \mathrm{ng} / \mathrm{ml}$ or less remifentanil combined with desflurane for decreasing concentrations of desflurane without significant side effects, during the "maintenance" phase, and not during the induction phase of general anesthesia. (Korean J Anesthesiol 2012; 63: 25-29)

Key Words: Desflurane, Remifentanil, Target-controlled infusion.

Received: September 8, 2011. Revised: 1st, October 4, 2011; 2nd, October 21, 2011; 3rd, November 29, 2011. Accepted: December 15, 2011. Corresponding author: Myoung-Keun Shin, M.D., Department of Anesthesiology and Pain Medicine, Samsung Changwon Hospital, 50, Hapsung-dong, Masanheiwon-gu, Changwon 630-522, Korea. Tel: 82-55-290-6072, Fax: 82-55-290-6379, E-mail: smkeun311@yahoo.co.kr (c) This is an open-access article distributed under the terms of the Creative Commons Attribution Non-Commercial License (http:// creativecommons.org/licenses/by-nc/3.0/), which permits unrestricted non-commercial use, distribution, and reproduction in any medium, provided the original work is properly cited. 


\section{Introduction}

Remifentanil can be used on patients with hepatic, renal dysfunction with severe liver, and renal diseases [1,2]. Hemodynamically, it drops the MAP and HR and reduces the CBF and ICP [3], and it is hydrolyzed by nonspecific esterase in blood and tissues. Thus, it does not accumulate in the body, It has a quick onset time and elimination time, and the risk involved with using remifentanil together with other general anesthetics in long surgeries is known to be low [4]. However, desflurane allows for a rapid induction of anesthesia, a rapid recovery of consciousness, and a rapid recovery of the general motor function [5].

In one study, remifentanil in combination with desflurane and $60 \% \mathrm{~N}_{2} \mathrm{O}$ was infused at target-controlled concentrations of $1 \mathrm{ng} / \mathrm{ml}$ and $3 \mathrm{ng} / \mathrm{ml} 5 \mathrm{~min}$ after the first surgical incision. The end-tidal concentration (ETC) of desflurane decreased to $2.7 \%$ and $2.0 \%$, respectively [6].

For the present study, the target-controlled effect-site concentrations of $1 \mathrm{ng} / \mathrm{ml}$ or $2 \mathrm{ng} / \mathrm{ml}$ remifentanil were each used together with desflurane for patients who underwent orthopedic or extremity surgeries and were expected to have similar MAC changes. The remifentanil groups were compared to a group in which desflurane was used alone in order to determine how effective ETC of desflurane during the anesthesia "maintenance" phase (most of the entire anesthesia phase) can be reduced while maintaining the MAP and reducing the risk of awareness during anesthesia.

\section{Materials and Methods}

The study protocol was approved by the Institutional Review Board based at the author's hospital. This study was carried out according to the principles of the Declaration of Helsinki

Table 1. Demographic Data of Patients and Duration of MGA (min)

\begin{tabular}{lccc}
\hline & $\begin{array}{c}\text { Group R1 } \\
(\mathrm{n}=30)\end{array}$ & $\begin{array}{c}\text { Group R2 } \\
(\mathrm{n}=28)\end{array}$ & $\begin{array}{c}\text { Group D } \\
(\mathrm{n}=30)\end{array}$ \\
\hline Age (yr) & $37.9 \pm 9.4$ & $38.2 \pm 9.0$ & $37.2 \pm 8.4$ \\
Sex (M/F) & $20 / 10$ & $21 / 7$ & $20 / 10$ \\
Weight (kg) & $61.9 \pm 10.3$ & $66.9 \pm 11.4$ & $67.3 \pm 11.4$ \\
Duration of & $66.2 \pm 16.9$ & $67.5 \pm 20.0$ & $68.0 \pm 17.7$ \\
MGA (min) & & &
\end{tabular}

MGA: the "maintenance" phase of general anesthesia [7] (from after a 10-15 min period of surgical incision to before a $10-$ min period at the end of the operation). Values are mean \pm SD except for sex. Group R1: patients received a $1 \mathrm{ng} / \mathrm{ml}$ effect-site target-controlled concentration of remifentanil with desflurane, Group R2: patients received a $2 \mathrm{ng} / \mathrm{ml}$ effect-site target-controlled concentration remifentanil with desflurane, Group D: patients received only desflurane without remifentanil infusion. There are no significant differences compared with group D.
2000, and written informed consent was obtained from all the participants before inclusion in the trial. Ninety ASA class I patients (age range: $20-49$ ) who were scheduled for orthopedic or extremity surgeries under general anesthesia (without a change of body positioning) and who were expected to have a blood loss lower than $200 \mathrm{ml}$ were eligible for the study.

We used a randomized, controlled clinical trial study design. Randomization into one of the three groups was based on an Excel random-number generation. For the patients in group $\mathrm{D}$, maintenance of anesthesia was done with desflurane only, and for those patients in groups R1 and R2, anesthesia was maintained with desflurane and remifentanil at $1 \mathrm{ng} / \mathrm{ml}$ and 2 $\mathrm{ng} / \mathrm{ml}$ effect-site target concentrations, respectively (Table 1 ).

All patients were transferred to the operating room without premedication. Anesthetic induction was performed by an intravenous (IV) administration of propofol $2 \mathrm{mg} / \mathrm{kg}$ and lidocaine $0.5 \mathrm{mg} / \mathrm{kg}$ for $1 \mathrm{~min}$ as inspiring oxygen $4-6 \mathrm{~L} / \mathrm{min}$. After the loss of consciousness, vecuronium $0.15 \mathrm{mg} / \mathrm{kg}$ IV was administered. Remifentanil $1 \mathrm{mg}$ (Ultiva ${ }^{\mathrm{TM}}$, GlaxoSmithKline, USA) was diluted with $50 \mathrm{ml}$ of normal saline and this was administered in Group R1 and R2 using the remifentanil TCI (MODULE DPS ORCHESTRA IS3, Fresenius Vial, France). The effect-site target concentration of remifentanil was $1 \mathrm{ng} /$ $\mathrm{ml}$ in group $\mathrm{R} 1$ and $2 \mathrm{ng} / \mathrm{ml}$ in group R2, and $4-6 \%$ of inspired desflurane was given at the same time. In group $\mathrm{D}$, remifentanil was not infused, but the patients were administered $7-9 \%$ of inspired desflurane (D-Vapor, Draeger, Germany or D-Tec Plus, Datex-Ohmeda, USA). After that, the patients were intubated.

To evaluate the arterial pressure, a 24- or a 22-gauge catheter was inserted into the radial artery after a modified Allen's test or a noninvasive blood pressure was used. To check the degree of cortical encephalographic suppression, the BIS apparatus (VISTA ${ }^{\mathrm{TM}}$, Aspect Medical System, Inc., USA) was placed. Maintenance anesthesia was done $\mathrm{O}_{2}$ and air was administered at $1-2 \mathrm{~L} / \mathrm{min}\left(\mathrm{FiO}_{2}=0.6\right)$. The mechanical ventilation was adjusted to keep the tidal volume $10 \mathrm{ml} / \mathrm{kg}$, the $\mathrm{PETCO}_{2}$ between 32 and $37 \mathrm{mmHg}$. Thirty minutes after the first administration of muscle relaxants, a peripheral nerve stimulator was used to evaluate the level of muscle relaxation. When additional relaxation was required, vecuronium $0.02 \mathrm{mg} /$ $\mathrm{kg}$ was administered.

The MAP and HR were recorded at 5-min intervals and the BIS was continuously monitored during the anesthesia "maintenance" phase [7], which was defined as from after the 10-15 min period of the first surgical incision to before the 10min period at the end of the operation. The ETC of desflurane was adjusted depending on the MAP and HR that was changed at every $5 \mathrm{~min}$. In all three groups, the third measurement of MAP and HR after the first surgical incision was set as the baseline. When the MAP or HR increased $10 \%$ or more, ETC 
of desflurane increased by 0.5 vol\%. When the MAP or HR decreased $10 \%$ or more, ETC of desflurane decreased by about 0.5 vol\%.

Fresh gas flow was set at $10 \mathrm{~L} / \mathrm{min}$ to obtain and maintain the designed ETC of desflurane rapidly. Once the desired ETC was obtained, the fresh gas flow was reduced to $2-4 \mathrm{~L} / \mathrm{min}$ for the whole procedure. This lasted approximately $2 \mathrm{~min} 30 \mathrm{sec}$ at a time.

During the study, patients were excluded from the study if their systolic blood pressure dropped to below $90 \mathrm{mmHg}$, their BIS rose to above 63 for even once or was between $60-62$ for more than 2 min during monitoring. Patients in the study were changed with another patient if their estimated blood loss was higher than $200 \mathrm{ml}$. The day after surgery, all the patients were visited for an examination and they were asked about the existence of awareness during surgery.

For intergroup comparisons, the normality of distribution of the collected data was first evaluated using the ShapiroWilk test. The normally distributed data was analyzed using the analysis of variance (ANOVA) followed by Tukey post hoc test, and the abnormally distributed data was analyzed using the Kruskal-Wallis test followed by Bonferroni correction. The differences in the mean arterial pressure, heart rate, BIS, and end-tidal desflurane concentration between the 3 groups were analyzed by a repeated measures analysis of variance (ANOVA). The descriptive variables were analyzed by $\chi^{2}$ test. A P value $<0.05$ was considered statistically significant. The data are reported as mean values with variability expressed as either SD in the tables or SE in the figures. Statistical analysis was performed with SPSS version 18.0 (SPSS Inc., Chicago, IL, USA).

\section{Results}

Two patients were excluded from the present study for the following reason: systolic blood pressure was below $90 \mathrm{mmHg}$ ( 1 in group R2) and the BIS was over 60 for 2 min or longer ( 1 in group R2) and the patient was treated immediately.

Upon visiting the patients the day after surgery, the authors asked about awareness during anesthesia and we found that none of the patients had possible awareness.

Age, height, weight, and the anesthesia maintenance phase showed no significant differences compared to those in the control group. As for the gender ratio, there were approximately twice as many males as females in each group (Table 1).

The MAP in group R2 was $84.9 \pm 5.9 \mathrm{mmHg}$, which showed a significant difference $(\mathrm{P}<0.05)$ when compared to group $\mathrm{D}(89.6$ $\pm 6.5 \mathrm{mmHg}$ ), however, there were no significant differences between group R1 and R2 and between group R1 and group D. The HR in group R2 was $67.5 \pm 8.3$ beats $/ \mathrm{min}$, which showed a significant difference $(\mathrm{P}<0.05)$ when compared to group $\mathrm{D}$
(75.3 \pm 6.8 beats $/ \mathrm{min}$ ). 3 patients in group $\mathrm{R} 1$ and 7 patients in group R2 were temporarily below 60 but above 50, however, they recovered without treatment. There were no significant differences regarding the BIS values.

The ETCs of desfluranes that were administered during surgery for group R1 and group R2 were $5.2 \pm 0.5$ vol\% and 4.4 $\pm 0.5 \mathrm{vol} \%$, respectively, which showed significant reducing effects of $34.2 \%$ and $44.4 \%$, respectively $(\mathrm{P}<0.001)$ compared to group D $(7.9 \pm 0.5$ vol\%). Group R2 compared to group R1 showed a significant difference $(\mathrm{P}<0.05)$ (Fig. 1).

\section{Discussion}

There have been several reports on using inhalational anesthetics in combination with opioids. Daniel et al. reported that fentanyl decreased the $\mathrm{MAC}_{\mathrm{BAR} \text { (blockade of autonomic response) }}$ ETC of desflurane when used with $\mathrm{N}_{2} \mathrm{O}$ [8]. Albertin et al. reported on remifentanil used in combination with desflurane and $60 \% \mathrm{~N}_{2} \mathrm{O}$ and infused remifentanil at target concentrations of $1 \mathrm{ng} / \mathrm{ml}$ and $3 \mathrm{ng} / \mathrm{ml}$ using TCI at $5 \mathrm{~min}$ after the first surgical incision and they found that the $\mathrm{MAC}_{\mathrm{BAR}}$ ETC was decreased to $2.7 \%$ and $2.0 \%$, respectively; this showed significant reducing effects of about $37 \%$ and $45 \%$, respectively [6]. When performing anesthesia induction, laryngeal manipulation and endotracheal intubation can cause severe hemodynamic changes, To prevent these changes, at least a 1.5 MAC anesthetic concentration is required [9], and depending on different stimuli, the systolic blood pressure and HR can greatly change [10]. In our pilot study, we assigned a group an effect-site target concentration of $3 \mathrm{ng} / \mathrm{ml}$

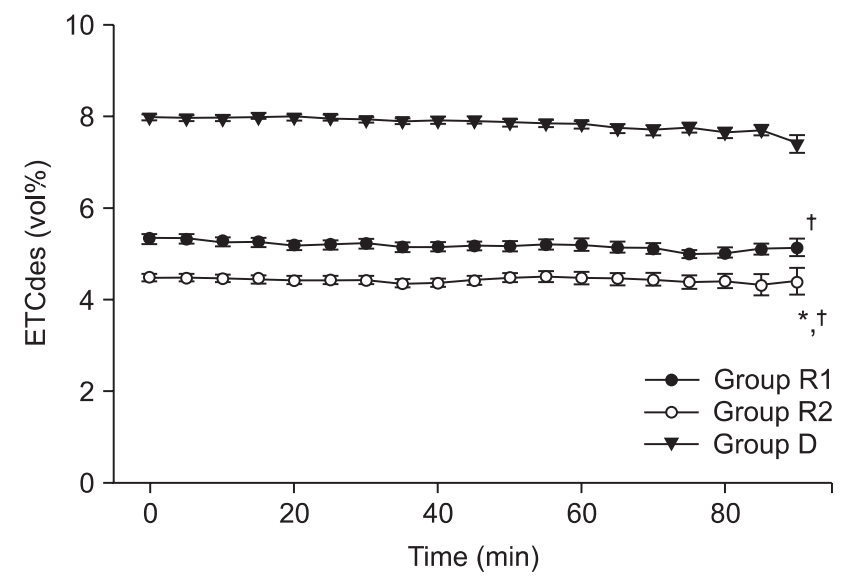

Fig. 1. End-tidal concentration of desflurane. Values are mean $\pm \mathrm{SE}$ at 5-min intervals during MGA. Group R1: patients received a $1 \mathrm{ng} /$ $\mathrm{ml}$ effect-site target-controlled concentration of remifentanil with desflurane, Group R2: patients received a $2 \mathrm{ng} / \mathrm{ml}$ effect-site targetcontrolled concentration of remifentanil with desflurane, Group D: patients received desflurane only without remifentanil infusion. ETCdes: End-tidal concentration of desflurane (vol\%). ${ }^{*} \mathrm{P}<0.05$ compared with group R1. ${ }^{\dagger} \mathrm{P}<0.001$ compared with group D. 
of remifentanil, as was done by Albertin et al. [6]. However, in the "maintenance phase," there were many cases (more than $30 \%$ ) where the systolic blood pressure was below $90 \mathrm{mmHg}$ with hypotension and the BIS values over 60 , these data did not allow the study to proceed. A systolic blood pressure drop below $90 \mathrm{mmHg}$ is not likely to occur during the anesthesia "induction phase" as this requires at least a 1.5 MAC. However, the concentration of $3 \mathrm{ng} / \mathrm{ml}$ remifentanil was considered too high for a stable "maintenance" phase, as in the present study.

"Recall or awareness" is a phenomenon where the patient under general anesthesia has dreams or suffers from nightmares. Avidan et al. showed that 2 of the 1941 patients clearly experienced awareness when the BIS was set at 40-60 and the end-tidal MAC was set at $0.7-1.3$ to reduce the risk of awareness in patients under general anesthesia [11]. This indicates that the adequate use of anesthetics and the BIS cannot completely prevent awareness. Albertin et al. stated that increasing the MAC by using $\mathrm{N}_{2} \mathrm{O}$ is rational for the prevention of explicit recall or awareness [6]. However, when Kil et al. [12] administered $\mathrm{N}_{2} \mathrm{O}$ every $15 \mathrm{~min}$, the administered $\mathrm{N}_{2} \mathrm{O}$ concentration that was raised from 0 to $33 \%, 50 \%$, and $67 \%$ at 15 min intervals did not significantly change the BIS value. Thus, $\mathrm{N}_{2} \mathrm{O}$ reportedly had hardly any effect on the BIS, which is unlike the other vapor anesthetics [12]. In reality though, if the $\mathrm{N}_{2} \mathrm{O}$ concentration had no effect on decreasing the BIS values, as compared to the combined use of remifentanil and desflurane with a dropped concentration of $52.5 \% \mathrm{~N}_{2} \mathrm{O}$ and $0.5 \mathrm{MAC}$, then the combined use of remifentanil with the same concentration as desflurane and without the use of $52.5 \% \mathrm{~N}_{2} \mathrm{O}$ would make the concentration of desflurane drop to approximately $3 \%$, which is a 0.5 MAC. Thus, it is predicted that the BIS values may appear to be greater with a combined use of desflurane, remifentanil, and $\mathrm{N}_{2} \mathrm{O}$ than without $\mathrm{N}_{2} \mathrm{O}$. As such, $\mathrm{N}_{2} \mathrm{O}$ was not used together with the combined use of desflurane and remifentanil in the present study.

For the appropriate BIS values, Flaishon et al [13]. reported that when thiopental and propofol were each administered, there were no conscious patients with a BIS under 58. The probability is $5 \%$ or less for a patient to return to consciousness within 50 seconds when the BIS is 65 or below [13]. Although Albertin et al. reported that patients with BIS values over 60 had stated that they were not aware at the visit the day after surgery [6], the Ethics Committee of our hospital chose a course of action that placed priority on the safety of the patients. Thus, to reduce such a risk of awareness, patients with a BIS value of 63 or above at least once or values from 60 to 62 for more than 2 minutes were excluded from the present study. In addition, for such patients, the BIS values were decreased and anesthesia was maintained by having the desflurane concentration immediately raised and the concentration of remifentanil reduced.
None of the patients who were visited the day after surgery responded with the slightest hint of recall or awareness during anesthesia.

In this study, ETCs of desfluranes that were administered during surgery for group R1 and group R2 were $5.2 \pm 0.5$ vol\% and $4.4 \pm 0.5$ vol\%, respectively. This showed significant reducing effects of $34.2 \%$ and $44.4 \%$, respectively ( $\mathrm{P}<0.001$ ), compared to group D $(7.9 \pm 0.5$ vol\%). Group R2 compared to group $\mathrm{R} 1$ showed a significant difference $(\mathrm{P}<0.05)$. However, as 2 patients were excluded from the study where $2 \mathrm{ng} / \mathrm{ml}$ was used and treated immediately, the present study's results lead us to believe that using remifentanil below $2 \mathrm{ng} / \mathrm{ml}$ of effect-site target concentration is considered to be safer in the "maintenance" phase, but not including the anesthesia induction phase. If one plans to decrease the use of the main anesthetics, such as desflurane, further, then supplicants such as propofol should be infused in the condition where both MAP and BIS values have been stabilized and maintained.

\section{References}

1. Tegeder I, Lötsch J, Geisslinger G. Pharmacokinetics of opioids in liver disease. Clin Pharmacokinet 1999; 37: 17-40.

2. Pitsiu M, Wilmer A, Bodenham A, Breen D, Bach V, Bonde J, et al. Pharmacokinetics of remifentanil and its major metabolite, remifentanil acid, in ICU patients with renal impairment. Br J Anaesth 2004; 92: 493-503.

3. Fukuda K. Opioids. In: Miller's anesthesiology. 7th ed. Edited by Miller RD: Philadelphia, Churchill Livingstone. 2009, pp 777-89.

4. Thompson JP, Rowbotham DJ. Remifentanil-an opioid for the 21st century. Br J Anaesth 1996; 76: 341-3.

5. Alonso Chico A, Rodríguez Fraile JR, Pacheco Jiménez A, Faraco Favieres M, Gutiérrez Rodríguez M, Maroto Ramos E. Comparative study of recovery times and psychomotor function after anesthesia with desflurane or isoflurane. Rev Esp Anestesiol Reanim 1998; 45: 184-8.

6. Albertin A, Dedola E, Bergonzi PC, Lombardo F, Fusco T, Torri G. The effect of adding two target-controlled concentrations of remifentanil on MACBAR of desflurane. Eur J Anaesthesiol 2006; 23: 510-6.

7. Willenkin RL, Polk SL. Management of general anesthesia. In: Miller's anesthesiology. 4th ed. Edited by Miller RD: San Francisco, Churchill Livingstone. 1994, pp 1052-3.

8. Daniel M, Weiskopf RB, Noorani M, Eger EI 2nd. Fentanyl augments the blockade of the sympathetic response to incision (MAC-BAR) produced by desflurane and isoflurane: desflurane and isoflurane MAC-BAR without and with fentanyl. Anesthesiology 1998; 88: 439.

9. Zbinden AM, Maggiorini M, Petersen-Felix S, Lauber R, Thomson DA, Minder CE. Anesthetic depth defined using multiple noxious stimuli during isoflurane/oxygen anesthesia. I. Motor reactions. Anesthesiology 1994 ; 80: 253-60.

10. Zbinden AM, Petersen-Felix S, Thomson DA. Anesthetic depth defined using multiple noxious stimuli during isoflurane/oxygen 
anesthesia. II. Hemodynamic responses. Anesthesiology 1994; 80: 261-7.

11. Avidan MS, Zhang L, Burnside BA, Finkel KJ, Searleman AC, Selvidge JA, et al. Anesthesia awareness and the bispectral index. N Engl J Med 2008; 358: 1097-108.

12. Kil HY, Chae BS, Lee SI, Choi YH, Lee SJ, Lee SW, et al. The effect of concentration of nitrous oxide on bispectral index and sedation score. Korean J Anethesiol 2000; 38: 220-4.

13. Flaishon R, Windsor A, Sigl J, Sebel PS. Recovery of consciousness after thiopental or propofol. Bispectral index and isolated forearm technique. Anesthesiology 1997; 86: 613-9. 